\title{
Presynaptic Inhibition of Excitatory Synaptic Transmission by Adenosine in Rat Hippocampus: Analysis of Unitary EPSP Variance Measured by Whole-Cell Recording
}

\author{
Carl R. Lupica, ${ }^{1}$ William R. Proctor, ${ }^{1,2}$ and Thomas V. Dunwiddie ${ }^{1,2}$ \\ 'Department of Pharmacology and Neuroscience Program, University of Colorado Health Sciences Center, Denver, \\ Colorado 80262 and ${ }^{2}$ Denver Veterans Administration Medical Center, Denver, Colorado 80220
}

\begin{abstract}
We have utilized the favorable signal-to-noise ratios provided by whole-cell recording, combined with variance analysis, to determine the pre- or postsynaptic actions of a variety of manipulations on unitary EPSPs evoked by low-intensity stimulation of afferents to CA1 pyramidal neurons in slices of hippocampus. Estimates of quantal content $\left(m_{\mathrm{cv}}\right)$ were determined by calculating the ratio of the squared average unitary EPSP amplitude (determined from 150-275 responses) to the variance of these responses $\left(M^{2} / \sigma^{2}\right)$, while quantal amplitudes $\left(q_{\mathrm{cv}}\right)$ were estimated by calculating the ratio of the response variance to average EPSP size $\left(\sigma^{2} / M\right)$. Estimates of $\boldsymbol{m}_{\mathrm{cv}}$ were highly correlated with those determined using the method of failures $\left(m_{f}\right)$. With paired stimulation (50 msec interpulse interval) there was a significant facilitation of the second unitary EPSP, accompanied by an increase in $\boldsymbol{m}_{\mathrm{cv}}$, but not $q_{\mathrm{cv}}$, suggesting that this facilitation was of presynaptic origin. Superfusion of hippocampal slices with various concentrations of adenosine, the A1-selective adenosine receptor agonist cyclohexyladenosine, or the $\mathrm{Ca}^{2+}$ channel blocker cadmium significantly reduced average unitary EPSP amplitudes and $\boldsymbol{m}_{\mathrm{cv}}$, without significantly altering $q_{c v}$ suggesting a presynaptic locus for this inhibition. The $50 \%$ effective concentration for the apparent presynaptic action of adenosine on $\boldsymbol{m}_{\mathrm{cv}}$ in the present study (5.7 $\mu \mathrm{M} ; 95 \%$ confidence limits $=\mathbf{4 . 2 - 7 . 7} \mu \mathrm{M}$ ) was significantly lower than its $\mathrm{EC}_{\mathrm{so}}$ for reducing conventional, large EPSPs (33 $\mu \mathrm{M}$; recorded with high-resistance microelectrodes), or extracellular field EPSPs $(29 \mu \mathrm{M})$, as previously reported by this laboratory. The glutamate receptor antagonist 6,7-dinitroquinoxaline-2,3-dione (DNQX) reduced average unitary EPSP amplitudes; in contrast to the above manipulations, it had no effect on $\boldsymbol{m}_{\mathrm{cv}}$, but significantly altered $q_{\mathrm{cv}}$, which is consistent with its presumed postsynaptic mechanism of action. We conclude from these data that adenosine presynaptically reduces synaptic strength at Schaffer collateral-commissural synapses in the hippocampus by diminishing the number of quanta released, not by reducing the size of these individual quanta or postsynaptic sensitivity to excitatory neurotransmitter. These results suggest that the
\end{abstract}

\footnotetext{
Received Jan. 16, 1992; revised Apr. 13, 1992; accepted Apr. 22, 1992.

This work was supported by NIDA Grant DA 02702 and NIH Grant NS 29173.

Correspondence should be addressed to Carl R. Lupica, Ph.D., Department of

Pharmacology, C-236, University of Colorado Health Sciences Center, 4200 Fast 9 th Avenue, Denver, CO 80262.

Copyright (C) 1992 Society for Neuroscience $0270-6474 / 92 / 123753-12 \$ 05.00 / 0$
}

mechanism by which adenosine inhibits synaptic transmission in the hippocampus is similar, if not identical, to the mechanism by which it inhibits synaptic transmission at the neuromuscular junction.

Adenosine has been noted as a potent inhibitor of neuronal activity in the mammalian brain based upon a number of studies examining its effects on spontaneous neural firing rates (see Phillis and $\mathrm{Wu}, 1981$, for review) and evoked synaptic responses (Schubert and Mitzdorf, 1979; Dunwiddie and Hoffer, 1980; Okada and Kuroda, 1980). While these actions of adenosine are well established, its source and distribution in the CNS are relatively unknown, although it seems to be tonically present and active under physiological conditions (Dunwiddie et al., 1981; Zetterstrom et al., 1982; Fredholm et al., 1984; Haas and Greene, 1988), and its extracellular concentrations can be elevated during periods of increased metabolic demand (Zetterstrom et al., 1982). The depression of synaptic transmission has been noted as one of the distinguishing characteristics of adenosine both in the mammalian CNS (Dunwiddie, 1985) and at the neuromuscular junction (Ginsborg and Hirst, 1972). It is at the neuromuscular junction that it has been possible to establish most conclusively, using quantal analysis of end-plate potentials at single ncrvc-muscle synapses, that adenosine reduces the average number of quanta of $\mathrm{ACh}$ released from the nerve terminal (i.e., quantal content, $m$ ), without affecting the size of these individual quanta ( $q$ ) (Ginsborg and Hirst, 1972; Ribeiro and Walker, 1975; Silinsky, 1984). In the CNS, the hypothesis that adenosine acts to diminish synaptic transmission via a presynaptic action has relied upon more indirect evidence since excitatory neurotransmitter release is typically evoked by the simultaneous activation of many presynaptic terminals, and since adenosine also acts to hyperpolarize CNS neurons (Greene and Haas, 1985; Trussell and Jackson, 1985, 1987; Proctor and Dunwiddie, 1987). Thus, the coexistence of both pre- and postsynaptic actions of adenosine has made it difficult to establish the relative contribution of each of these possibilities in regulating the overall degree of neuronal excitability. Several possible explanations exist to account for the inhibition of EPSPs activated through stimulation of excitatory afferents of CA1 pyramidal neurons in the hippocampus. Presynaptically, adenosine may decrease neurotransmitter release by reducing the number of vesicles released upon stimulation, by limiting the amount of excitatory transmitter in each vesicle, or by diminishing the number of activated synapses. Postsynaptically, adenosine could reduce neuronal sensitivity to the excitatory trans- 
A.

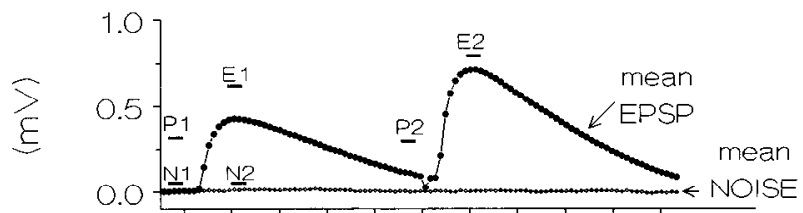

B.

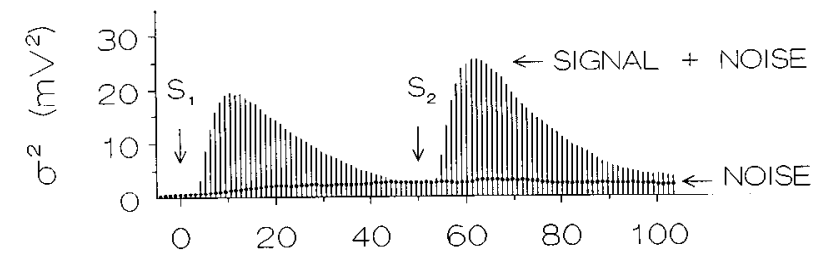

\section{TIME (msec)}

Figure 1. Measurement of unitary EPSPs and a comparison of noisecontaminated signal and noise variances $\left(\sigma^{2}\right)$ from a single CAl pyramidal neuron using whole-cell recording. $A$ shows the digital average of 100 EPSP responses (mean EPSP) and 100 samples of baseline noise (mean NOISE). Synaptic responses were evoked by two stimuli separated by $50 \mathrm{msec}\left(S_{1}\right.$ and $S_{2}$, as indicated in $\left.B\right)$. EPSP amplitudes were determined by calculating the difference between mean signal amplitude during a $3 \mathrm{msec}$ period centered on the peak of each response ( $E I$ and $E 2)$ and a baseline period immediately before the stimulus artifact $(P I$ and $P 2$ ). Noise amplitudes were determined by calculating the difference between periods $N 1$ and $N 2$ on nonstimulus trials. $B$ illustrates the variance of the averaged evoked response (SIGNAL + NOISE, vertical lines), shown in $A$, prior to subtraction of the noise variance (NOISE, horizontal line). Note that the variance associated with noise was much smaller than that associated with the evoked potentials.

mitter, decrease the excitatory conductance associated with glutamate receptors, or activate other ion channels that would shunt the EPSP recorded at the pyramidal neuron soma. Alternatively, some combination of these pre- and postsynaptic factors may account for the inhibition produced by adenosine.

Statistical analysis of synaptic variability is one technique that has recently been used in the hippocampus to determine whether alterations in synaptic efficacy are derived from pre- or postsynaptic sources (Bekkers and Stevens, 1990; Malinow and Tsien, 1990; Foster and McNaughton, 1991). Thesc statistical techniques together with the use of the low-noise whole-cell recording configuration to record "unitary" EPSPs (Friedlander et al., 1990) from hippocampal CAl pyramidal neurons have permitted us to evaluate the presynaptic versus postsynaptic actions of a variety of pharmacological manipulations. By comparing two measures of synaptic efficacy, one sensitive only to presynaptic changes in neurotransmitter release and the other sensitive to presynaptic and postsynaptic changes, we have found that adenosine acts predominantly at the excitatory amino acid nerve terminal to reduce synaptic transmission.

A portion of these results have appeared in preliminary form (Dunwiddie et al., 1991).

\section{Materials and Methods}

Hippocampal slice preparation. Experiments were performed using transverse hippocampal slices of $400 \mu \mathrm{m}$ thickness, obtained from male Sprague-Dawley rats, weighing between 120 and 160 gm (Sasco, Omaha, $\mathrm{NE}$ ). Slices were cut in pregassed, $4^{\circ} \mathrm{C}$ artificial cerebrospinal fluid (aCSF), using cither a vibrating tissue slicer (Technical Products International, St. Louis, MO) or a Sorvall tissue chopper (Newtown, CT), as described previously (Lupica et al., 1990). These slices were then transferred to a beaker containing aCSF, which was constantly aerated with a $95 \% \mathrm{O}_{2}$, $5 \% \mathrm{CO}_{2}$ mixture at $32^{\circ} \mathrm{C}$, and left undisturbed for at least $1 \mathrm{hr}$ prior to whole-cell recording. The aCSF consisted of (in $\mathrm{mM}$ ) $\mathrm{NaCl}, 126 ; \mathrm{KCl}$, $3.0 ; \mathrm{MgCl}_{2}, 1.5 ; \mathrm{CaCl}_{2}, 2.4 ; \mathrm{NaH}_{2} \mathrm{PO}_{4}, 1.2 ; \mathrm{NaHCO}_{3}, 26 ;$ D-glucose, 11 ; at $\mathrm{pH}$ 7.4. When testing procedures were begun, slices were placed in a recording chamber $(\sim 0.5 \mathrm{ml}$ volume) and submerged with a constant flow of oxygenated $\left(95 \% \mathrm{O}_{2}, 5 \% \mathrm{CO}_{2}\right)$, preheated aCSF $\left(33 \pm 1{ }^{\circ} \mathrm{C}\right)$ at a flow rate of $2 \mathrm{ml} / \mathrm{min}$.

Electrophysiological recording. Intracellular recordings of membrane potentials were obtained using a bridge circuit electrometer (Axoclamp2A, Axon Instruments, Burlingame, CA). Membrane potentials, not membrane currents, were measured due to the superior signal-to-noise ratio this method provides over the whole-cell voltage clamp, and because it is unlikely that responses to individual quanta interact in a nonlinear fashion. Whole-cell electrodes were pulled in three stages from borosilicate (Omega-dot) capillary tubing (i.d., $1.12 \mathrm{~mm} ; 0 . \mathrm{d} ., 1.5 \mathrm{~mm}$; Glass Company of America, Bargaintown, NJ) using a Flaming/Brown micropipette puller (P-87; Sutter Instrument Co., Novato, CA). These electrodes had resistances of 4-6 M $\Omega$ when filled with the following solution (in $\mathrm{mM}$ ): $\mathrm{CaCl}_{2}, 0.5 ; \mathrm{MgCl}_{2}, 2.0 ; \mathrm{KCl}$, potassium gluconate, 135.0; EGTA, 1.0; HEPES, 10.0; ATP, 2.0; at pH 7.2-7.4.

Pyramidal neurons were located in the slice by monitoring the voltage change in response to a $-0.1 \mathrm{nA}, 20$-msec-duration, square-wave current pulse passed through the whole-cell electrode. As this electrode was advanced through the stratum pyramidale in area $\mathrm{CA} 1$, an increase in resistance (observed as an increase in voltage) was seen when a cell was encountered. Negative pressure was then applied to the patch pipette, and a seal formed between the electrode tip and the cell membrane. When the membrane patch resistance reached $\geq 1 \mathrm{G} \Omega$, the membrane was ruptured by further application of negative pressure, and recordings commenced in the whole-cell configuration. Whole-cell membrane input resistance was determined by monitoring the membrane response to current pulses immediately following rupture of the membrane patch.

Synaptic stimulation was delivercd using a bipolar, twisted tungsten wire electrode (monophasic, $0.1 \mathrm{msec}$ pulses of $2-5 \mathrm{~V}$ ), placed on the stratum radiatum layer of the slice within approximately $1.5-2.0 \mathrm{~mm}$ of the recording electrode. Unitary EPSPs were evoked using paired

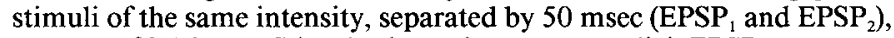
at a rate of $0.167 \mathrm{~Hz}$. Stimulus intensity was set to elicit EPSP ${ }_{1}$ responses that could be readily distinguished from baseline noise on $80-95 \%$ of the trials. All electrophysiological signals were digitized at $7 \mathrm{kHz}$ and stored on a hard disk drive residing in an AT-type personal computer, using a computer program developed in this laboratory (NEUROPRO; R.C. Electronics, Goleta, CA). Resting membrane potential was continually monitored using a chart recorder (Gould Electronics, Cleveland, $\mathrm{OH})$.

To reduce the influence of GABA-mediated inhibitory postsynaptic potentials (IPSPs) on unitary EPSPs, the GABA $\mathrm{A}_{\mathrm{A}}$ receptor antagonist bicuculline methiodide (10 $\mu \mathrm{M}$; Sigma, St. Louis, MO) was present in the aCSF throughout each experiment. Also, to reduce the degree of spontaneous synaptic activity in the CAl pyramidal neurons, and to prevent drug effects mediated by receptors located on CA3 neurons from altering axonal excitability, the CA3 region of each hippocampal slice was removed using a scalpel blade.

Data collection. Figure $1 \mathrm{~A}$ illustrates the procedures for measuring unitary EPSP and noise amplitudes. Peak EPSP amplitudes were measured by calculating the difference between average signal amplitude during a $3 \mathrm{msec}$ period (approximately 21 digitized points) centered on the peak of each response (E1 and E2) and a $3 \mathrm{msec}$ baseline period immediately prior to the stimulus artifacts (PI and P2). The amplitude of the background recording noise was determined by calculating the difference between $3 \mathrm{msec}$ periods corresponding to the $\mathrm{P} 1$ and $\mathrm{E} 1$ periods on nonstimulus trials ( $\mathrm{N} 1$ and $\mathrm{N} 2$ ). Nonstimulus trials were alternated with stimulus trials. Determination of peak EPSP locations were obtained by averaging $\sim 100$ consecutive responses and centering the $3 \mathrm{msec}$ measurement period upon the largest value of the response. Each sweep was then reanalyzed using these settings. Between 150 and 275 response and noise traces were collected for each recording epoch (control, drug, and washout periods) and used in the subsequent statistical analyses. In addition, since the statistical estimations of synaptic efficacy relied upon favorable signal-to-noise ratios, we established a criterion that during the control epoch the contribution to the total variance (i.e., the noise-contaminated signal variance) made by the background recording noise must be $<30 \%$. Cells not meeting this criterion were not included in this study.

Drugs. Adenosine and cadmium chloride were purchased from Sigma (St. Louis, MO). 6,7-dinitroquinoxaline-2,3-dione (DNQX) was pur- 
chased from Tocris Neuramin (Essex, UK). The A1 adenosine agonist cyclohexyladenosine (CHA) was purchased from Calbiochem (La Jolla, CA).

\section{Results}

The average resting membrane potentials ( $\pm 1 \mathrm{SEM}$ ) of $57 \mathrm{CAl}$ pyramidal neurons in which stable whole-cell recordings were obtained for at least $20 \mathrm{~min}$ was $-65.5 \pm 0.6 \mathrm{mV}$, while the average membrane input resistance of 46 of these cells was 117.4 $\pm 3.9 \mathrm{M} \Omega$. This resting membrane potential is slightly higher than that recorded from the same cell type using conventional high-resistance microelectrodes $(-62.6 \pm 1.0 \mathrm{mV} ; n=28)$; the input resistance is much higher than that recorded with highresistance microelectrodes in our laboratory $(29.7 \pm 3.1 \mathrm{M} \Omega ; n$ $=12$ ). Since the number of responses necessary for accurate estimation of synaptic variability within each epoch was large (Martin, 1966; Hubbard et al., 1969), it was necessary to record stable average EPSP amplitudes, in some instances, for periods up to $2 \mathrm{hr}$. Additionally, we required that $<30 \%$ of total variance of the unitary EPSPs be derived from background noise. Twenty-eight of the 57 pyramidal cells met both of these criteria and were included in the statistical estimates of the quantal parameters.

Response variability. A unique feature of the unitary EPSPs was that, despite relatively stable average EPSP amplitudes during any single recording epoch, they showed a high degree of variability from trial to trial. This variability is illustrated in Figure $1 B$, where the total variance of 100 responses in a single cell (i.e., noise-contaminated signal variance) is plotted on the same scale as the noise variance. Another index of the variability of these responses is the coefficient of variation ( $\mathrm{CV}=\mathrm{SD}$ / mean). We examined the CV for unitary EPSPs (mean amplitude of $0.59 \pm 0.03 \mathrm{mV} ; n=16$ cells) and found that they had an average $C V$ of 0.621 (range, $0.440-0.961$ ). These $C V$ values compare favorably with those observed at single synapses in pyramidal cell culture and in hippocampal slices (Bekkers et al., 1990). In comparison to these unitary EPSPs, a sample of extracellular field EPSPs in CA1 had a mean amplitude of 0.74 $\pm 0.03 \mathrm{mV}$ and an average $\mathrm{CV}$ of 0.050 (range, $0.025-0.082$; $n=10$ slices). Large intracellular EPSPs recorded from CA1 pyramidal neurons with whole-cell electrodes (mean EPSP amplitude $=13.53 \pm 1.43 \mathrm{mV}$ ) had an average $\mathrm{CV}$ of $0.063(\mathrm{CV}$ range, $0.048-0.096 ; n=8$ cells). This significant $10-12$-fold higher variability in unitary EPSP responses, as compared to field EPSPs or "macroscopic" intracellular EPSPs $(p<0.0001$, ANOVA), might arise from noise in the recording system (e.g., variations in the quality of the pipette-membrane seal) or shortterm fluctuations in the efficacy of synaptic transmission. However, this variability cannot be attributed entirely to recording factors, because, as Figure 1 illustrates for a single cell, the unitary EPSP response variance was found to be much higher than the background recording noise variance. Overall, from a total of 12 pyramidal neurons, the noise variance contributed only $10.9 \pm 1.7 \%$ to the total variance of EPSP ${ }_{1}$. Therefore, approximately $90 \%$ of the unitary EPSP variability appears to be of biological origin, and there are a variety of ways in which this might arise. Some of these are (1) variation in the number of quanta released upon stimulation, (2) axonal conduction failure, (3) variation in the size of individual quanta, (4) variation in postsynaptic sensitivity, and so on. The last possibility, although plausible, seems unlikely because mechanisms that could produce such rapid changes in postsynaptic sensitivity, to our knowledge, have not been described. Also, responses to locally applied glutamate do not typically show this type of variability (Proctor and Dunwiddie, 1987; Hvalby, 1990). The first three possibilities are obviously presynaptic in origin, and the majority of our experiments were designed to test the hypothesis that one of these presynaptic mechanisms was the target of synaptic modulators. If the variability we observed in unitary EPSPs arises from presynaptic factors, then agents that change the variability must be working through presynaptic mechanisms.

Statistical analysis. In order to characterize the variability of these responses more formally, one must have a measure of this intrinsic variability that is independent of the absolute response amplitude, such as the CV. However, a more useful measure of synaptic responses is $1 / \mathrm{CV}^{2}$, which we refer to as $m m_{\mathrm{cv}}$. This parameter can also be calculated as

$$
m_{\mathrm{cv}}=M^{2} /\left(\sigma_{r}^{2}-\sigma_{n}^{2}\right)=M^{2} / \sigma^{2},
$$

where $M$ is the mean EPSP amplitude, $\sigma_{r}^{2}$ is equal to the noisecontaminated EPSP variance, and $\sigma_{n}^{2}$ is the background noise variance. This is a measure of synaptic variability that is insensitive to changes in postsynaptic sensitivity (e.g., if a receptor antagonist reduced every response by $50 \%$, this parameter would be unchanged), but would be sensitive to the presynaptic factors responsible for EPSP variability (Martin, 1966; Hubbard et al., 1969; Bekkers and Stevens, 1990; Malinow and Tsien, 1990; Foster and McNaughton, 1991). It should be stressed that this parametcr $\left(m_{\mathrm{cv}}\right)$ is a unitless index of variability that makes no assumptions as to the source of the variance. However, if the source of the variability is in the number of quanta released, and if the number of quanta released follows a binomial distribution, then it can be shown that

$$
m_{\mathrm{cv}}=M^{2} / \sigma^{2}=N p /(1-p),
$$

where $p$ is the probability of the release of a quantum of transmitter and $N$ is the number of quanta available for release. If release probability is very small $(p<<1.0)$, then this parameter reduces to

$$
\begin{aligned}
m_{\mathrm{cv}}=M^{2} / \sigma^{2}- & N p /(1-p) \\
& \approx N p=m \quad \text { (mean quantal content). }
\end{aligned}
$$

While the parameter $m_{\mathrm{cv}}$ is useful because it requires few assumptions as to the sources of synaptic variability, it is complicated by the fact that it is subject to crrors of mcasurement when sample sizes are small or when signal-to-noise ratios are not favorable (Martin, 1966). Additionally, this parameter assumes that the responses to individual quanta at all activated release sites are of uniform size (Korn and Faber, 1991).

Another parameter can be calculated using this response variability:

$$
q_{\mathrm{cv}}=\sigma^{2} / M=(1-p) v z,
$$

where $v$ is the vesicular content and $z$ is the postsynaptic sensitivity to the transmitter. Again, if release probability is very small ( $p \ll 1.0$ ), then this parameter will reduce to

$$
q_{\mathrm{cv}}=\sigma^{2} / M=(1-p) v z \approx v z=q \quad \text { (quantal size). }
$$

It should be noted that the estimator of mean quantal content ( $m_{\mathrm{cv}}$ ) is sensitive to changes in $N$ and $p$, which are both presynaptic parametcrs, but will not be affected by changes in $v$ (vesicular content), which is also a presynaptic parameter, or by 


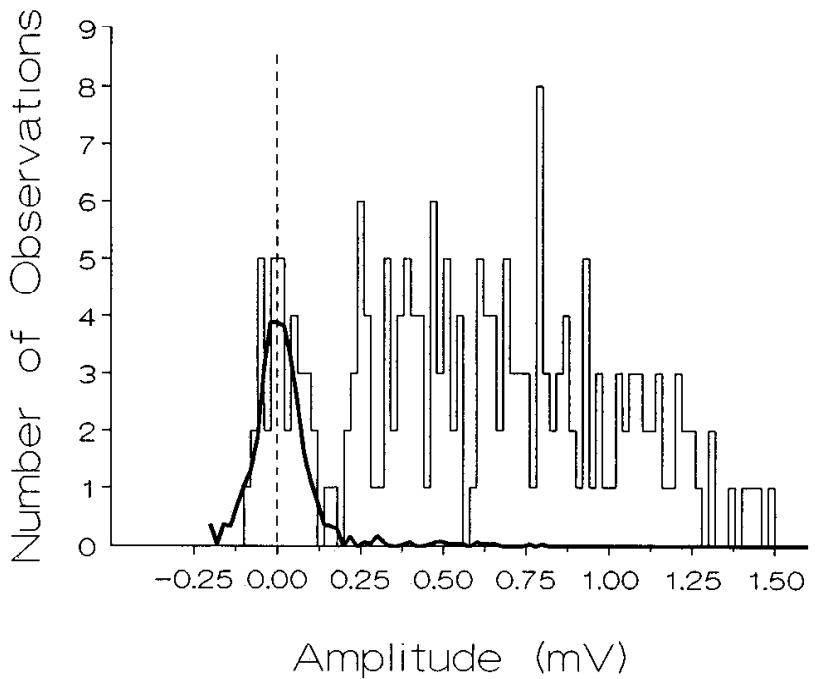

Figure 2. Representative noise (superimposed heavy line) and noisecontaminated unitary EPSP distributions recorded from a single CA1 pyramidal neuron in drug-free aCSF. The noise distribution was scaled to have the same number of negative responses as the noisc-contaminated EPSP distribution. Note that the noise histogram is symmetrical about a mean of 0 (broken vertical line); in this case there appears to be a clear break between failures (i.e., responses $<0.125 \mathrm{mV}$ ), and trials on which evoked responses were seen (i.e., responses $>0.200 \mathrm{mV}$ ). Bin width, $20 \mu \mathrm{V}$.

postsynaptic sensitivity $(z)$, if $q$ is invariant across all activated synapses. The estimator of quantal size $\left(q_{\mathrm{cv}}=\sigma^{2} / M\right)$ can be affected by the presynaptic parameter $v$ (vesicular content) and by the postsynaptic parameter $z$ (transmitter sensitivity). Thus, if $v$ remains constant, then $q_{\mathrm{cv}}$ will change linearly with changes in postsynaptic sensitivity.

Another approach that has been used to determine mean quantal content at synapses where the postsynaptic response to presynaptic stimulation is sometimes absent, is the method of failures, originally described by del Castillo and Katz (1954a,b), according to the equation

$$
m_{f}=\ln \left(N / n_{0}\right),
$$

where $N$ is total number of stimulation trials within an epoch and $n_{0}$ is the total number of failures within the same epoch (Martin, 1966). Figure 2 illustrates that the separation between the noise amplitude distribution and the noise-contaminated response distribution was sufficient to permit us to distinguish synaptic failures from background recording noise under most conditions. Also, since the noise amplitudes were normally distributed (Fig. 2), the total number of failures was determined by doubling the number of responses that were less than zero and adding those equal to zero (Sayer et al., 1989, 1990; Foster and McNaughton, 1991). In the case of the neuromuscular junction, $m_{f}$ corresponds quite closely to $m_{\mathrm{cv}}$ and appears to be an accurate estimator of mean quantal content. With unitary responses in hippocampus the interpretation of $m_{f}$ is less clear. However, if the occurrence of failures is related to some presynaptic event (e.g., axonal conduction failure, failure of the nerve terminal to release transmitter, etc.), then experimental manipulations that change $m_{f}$ must be affecting the presynaptic side of the synapse.

Effects of synaptic facilitation on $\mathrm{m}_{c v}$ and $\mathrm{q}_{c v}$. The preceding analysis suggested that $m_{\mathrm{cv}}$ is a parameter that should be altered by agents that modify synaptic transmission at a presynaptic site, whereas effects on $q_{\mathrm{cv}}$ should reflect changes in pre- and/or postsynaptic sensitivity. In our initial experiments, we examined these hypotheses using treatments whose sites of action are relatively well understood.

One form of short-term synaptic plasticity that has been suggested to be of presynaptic origin is that of paired-pulse facilitation (del Castillo and Katz, 1954a; Creager et al., 1980; Hess et al., 1987; Foster and McNaughton, 1991). In the present study, paired stimulation of afferents to CAl resulted in the facilitation of EPSP 2 in every cell tested ( $n=27$; examples from single cells, Figs. $1,3 D, 4 D, 5 D)$, with an average increase in $\mathrm{EPSP}_{2}$ to $158 \pm 12 \%$ of $\mathrm{EPSP}_{1}(n=27$ cells; $p<0.0001$, ANOVA). This facilitation was also accompanied by a significant average increase in $m_{\mathrm{cv}}$ to $177 \pm 18 \%$ of control $(p<$ 0.0001 , ANOVA), while $q_{\mathrm{cv}}$ calculated for $\mathrm{EPSP}_{2}$ remained unaltered by the preceding stimulation $\left(100 \pm 12 \%\right.$ of EPSP $\left._{1}\right)$.

Effects of DNQX on $\mathrm{m}_{c v}$ and $\mathrm{q}_{c v}$ DNQX is a glutamate receptor antagonist that should reduce the size of unitary EPSPs by an action at a postsynaptic site. Thus, we would predict that DNQX should reduce $q_{\mathrm{cv}}$ and have no effect upon $m_{\mathrm{cv}}$. As Figure 3 illustrates for a single pyramidal neuron, DNQX $(1 \mu \mathrm{M})$ reduced the average amplitude of EPSP ${ }_{1}$ to approximately one-half its previous amplitude, without altering $m_{\mathrm{cv}}$ (Fig. $3 B$ ). DNQX did, however, cause a marked decrease in $q_{\mathrm{cv}}$, reducing this parameter more than threefold (Fig. 3C). For all cells tested $(n=5)$, DNQX reduced the average $\mathrm{EPSP}_{1}$ response to $32 \pm 2 \%$ of control, and that of $\mathrm{EPSP}_{2}$ to $29 \pm 4 \%$ of control. The average reductions in $q_{\mathrm{cv}}$ for $\mathrm{EPSP}_{1}$ and $\mathrm{EPSP}_{2}$ to $25 \pm 4 \%$ of control and $30 \pm 9 \%$ of control, respectively, were statistically significant $(p<0.0001$, ANOVA), but DNQX had no significant effect on $m_{\mathrm{cv}}(112 \pm$ $35 \%$ of control and $90 \pm 29 \%$ of control, EPSP and $_{1} \mathrm{EPSP}_{2}$, respectively). These results suggest that DNQX acts to reduce mean EPSP amplitude by decreasing the quantity, $v$ (vesicular neurotransmitter content), or, more likely, by changing the postsynaptic sensitivity to glutamate $(z)$ (Andreasen et al., 1988, 1989; Herreras et al., 1989).

Effects of cadmium on $\mathrm{m}_{c v}$ and $\mathrm{q}_{c v}$. In order to determine the effect on $m_{\mathrm{cv}}$ and $q_{\mathrm{cv}}$ of decreasing average EPSP amplitudes via a presumed presynaptic mechanism, we examined the actions of the $\mathrm{Ca}^{2}$ channel blocker cadmium (Hille, 1992). Figure $4 D$ shows a single CA1 pyramidal neuron in which cadmium (10 $\mu \mathrm{M})$ reduced the average amplitude of $\mathrm{EPSP}_{1}$ and $\mathrm{EPSP}_{2}$. Unlike DNQX, however, cadmium reduced $m_{\mathrm{cv}}$ without altering $q_{\mathrm{cv}}$ (Fig. $4 A, B$ ). Figure $4 C$ illustrates the relationship between $m_{\mathrm{cv}}$ and average EPSP $_{1}$ amplitude $(M)$ in this same neuron, and shows that $M$ and $m_{\mathrm{cv}}$ change in parallel. In five pyramidal neurons tested with cadmium, EPSP $\mathrm{E}_{1}$ and $\mathrm{EPSP}_{2}$ amplitudes were reduced to $46 \pm 7 \%$ of control and $58 \pm 10 \%$ of control, respectively, while $m_{\mathrm{cv}}$ was reduced to $47 \pm 12 \%$ of control and $56 \pm 10 \%$ of control. There was no significant change in $q_{\mathrm{cv}}$ for these same cells $(94 \pm 12 \%$ of control and $105 \pm 16 \%$ of control,

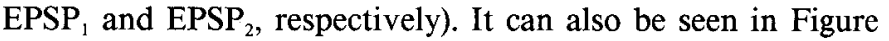
$4 C$ that the decrease in average EPSP amplitude $(M)$ caused by cadmium can be explained quantitatively by a decrease in $m_{\mathrm{cv}}$.

Effects of adenosine on $\mathrm{m}_{c v}$ and $\mathrm{q}_{c v}$. Like cadmium, the primary effect of adenosine was to reduce $m_{\mathrm{cv}}$ without affecting $q_{\mathrm{cv}}$. The effects of adenosine ( $5 \mu \mathrm{M}$ ) on a single CAl pyramidal neuron can be seen in Figure 5. The mean unitary EPSP was reduced by adenosine, and this effect was rapidly reversed by washing with control aCSF (Fig. $5 A$ ). It can also be seen that adenosine reduced the presynaptic parameter $m_{\mathrm{cv}}$ (Fig. $5 B$ ) in parallel with its actions upon unitary EPSP amplitude. Adenosine had no 

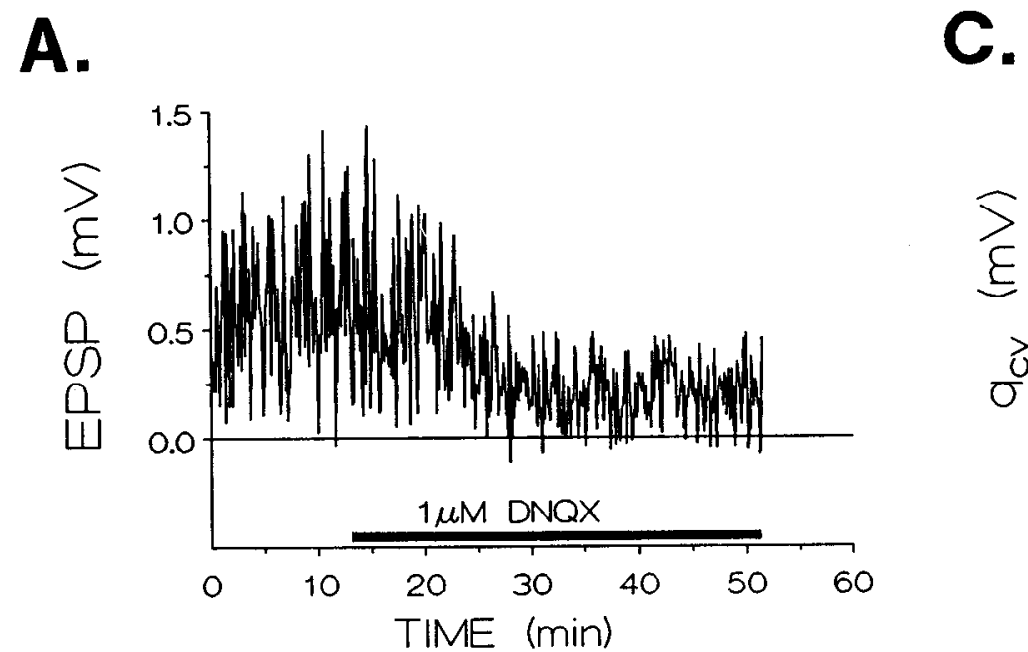

B.
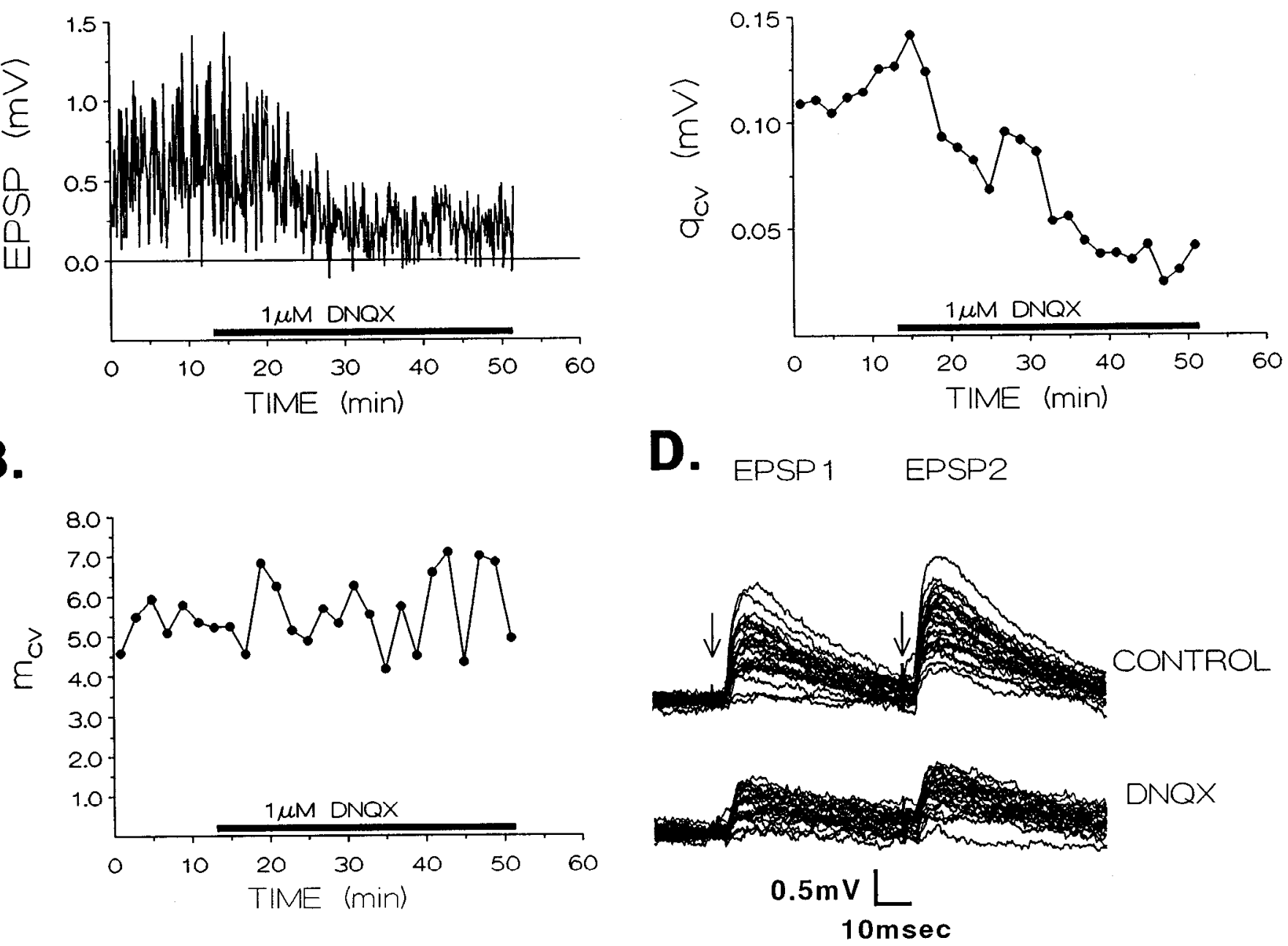

Figure 3. Effects of DNQX on EPSP $_{1}$ from a single CA1 pyramidal neuron. $A$ illustrates the time course of changes in EPSP that $_{1}$ occurred during superfusion with DNQX. Recovery from the effect of DNQX was not examined due to the extremely slow washout of this drug. DNQX reduced the average amplitude of the EPSPs, and reduced the variability of the responses as well. $B$, Time course of the effect of DNQX on mean quantal content $\left(m_{\mathrm{cv}}\right)$ calculated for successive groups of 20 responses using the techniques described in Materials and Methods. Note the lack of effect of DNQX upon this parameter and the high degree of variability of $m_{\mathrm{cv}}$, which is a consequence of the relatively small sample size used to estimate this parameter (Hubbard et al., 1969). $C$, Time course of the effect of DNQX on quantal amplitude $\left(q_{\mathrm{cv}}\right)$ calculated over the same periods as in $B$. As can be seen, the effect of DNQX was to reduce $q_{\mathrm{cv}}$, which could reflect either a change in vesicular neurotransmitter content or a change in postsynaptic sensitivity. The latter effect would be consistent with the known ability of DNQX to block postsynaptic receptors. $D$, Thirty consecutive unitary EPSP responses, representing those from which the data in $A-C$ are derived, are shown prior to and during DNQX application. Note the marked reduction in the amplitude of the EPSP responses during DNQX application. In this figure and in Figures 4 and 5 , the arrows mark the times of synaptic stimulation.

effect upon the parameter $q_{\mathrm{v}}$ in this cell (Fig. 50 ). The overall effect of $5 \mu \mathrm{M}$ adenosine on five cells was to reduce the average amplitude of EPSP, to $40 \pm 7 \%$ of control and the average $m_{\mathrm{cr}}$ to $42 \pm 10 \%$ of control, while the average $\mathrm{EPSP}_{2}$ amplitude was reduced to $44 \pm 9 \%$ of control, and average $m_{\mathrm{cv}}$ for $\mathrm{EPSP}_{2}$, to $30 \pm 7 \%$ of control. Figure 6 shows that the effect of adenosine upon $m_{\mathrm{cv}}$ was concentration dependent, with an $\mathrm{EC}_{50}$ for the reduction in $m_{\mathrm{cv}}$ of $5.7 \mu \mathrm{M}(95 \%$ confidence limits $=4.2-7.7$ $\mu \mathrm{M})$. This $\mathrm{EC}_{50}$ value is significantly lower than $\mathrm{EC}_{50}$ values reported by this laboratory for the inhibition of CA1 field EPSPs $(29 \mu \mathrm{M})$ or large intracellular EPSPs, recorded with conventional high-resistance microelectrodes $(33 \mu \mathrm{M})$ (Dunwiddie and Hoffer, 1980; Proctor and Dunwiddie, 1987). At no concentration did adenosine significantly affect $q_{\mathrm{c} .}$. Significant effects of aden- osine on resting membrane potential were not observed at any concentration $(102 \pm 3 \%$ of control).

Previous studies have shown that both $\mathrm{A} 1$ and $\mathrm{A} 2$ adenosine receptors exist in the hippocampus, and that the pre- and postsynaptic electrophysiological effects of adenosine appear to be mediated by Al receptors (Dunwiddie and Fredholm, 1989; Lupica et al., 1990). However, adenosine is not a particularly selective agonist for $\mathrm{A} 1$ or $\mathrm{A} 2$ adenosine receptors. Furthermore, it was possible that the actions of adenosine upon the presynaptic measure $m_{\mathrm{cv}}$ were due to intracellular receptor-mediated, or non-receptor-mediated metabolic effects of this purine. Thus, in an effort to better characterize the mechanisms underlying the reductions in $m_{\mathrm{cv}}$, we utilized the adenosine agonist CHA $(5 \mathrm{nM})$, which is highly selective for $\mathrm{Al}$ receptors and a poor 

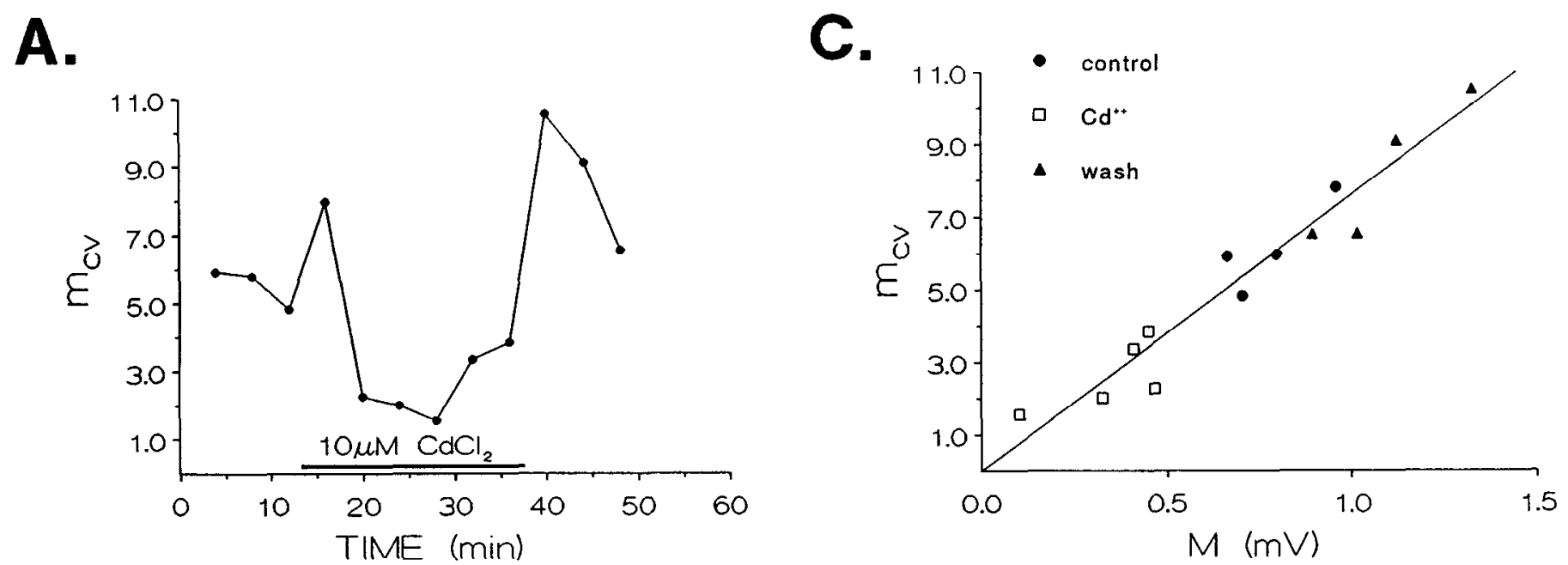

B.
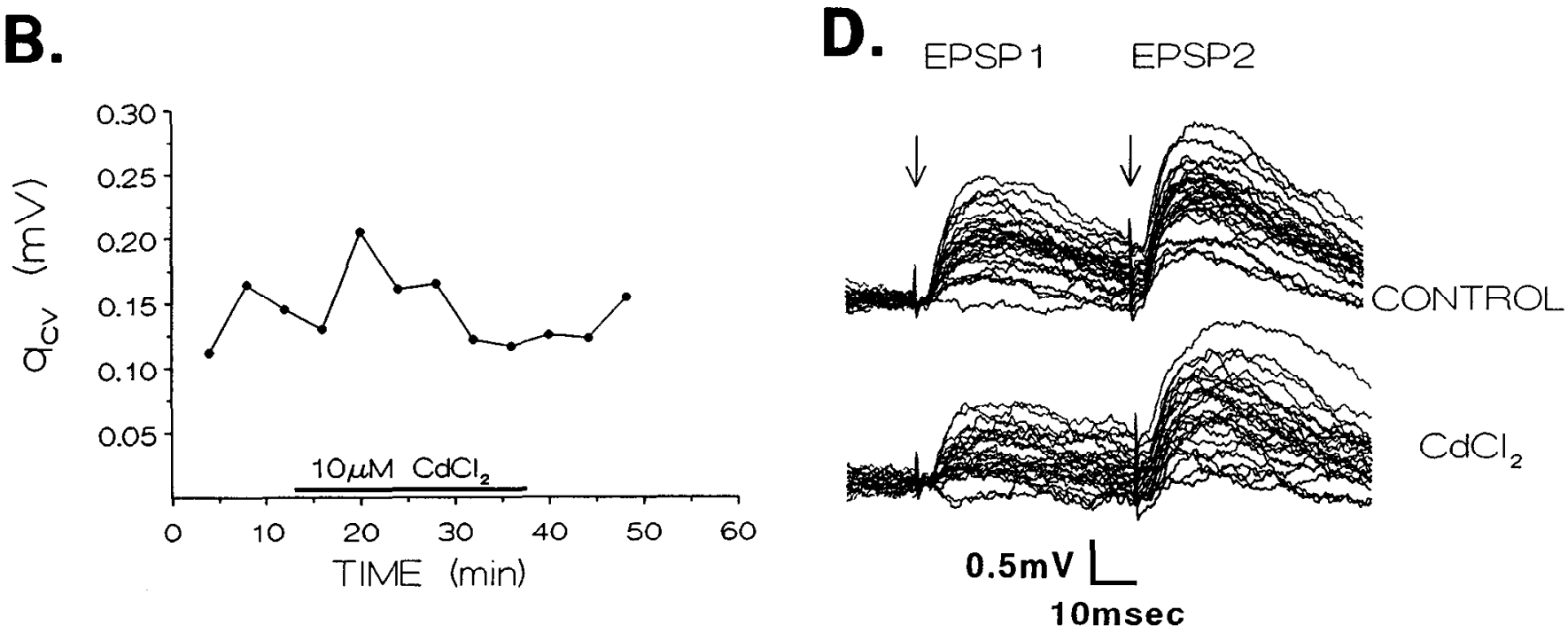

Figure 4. Effects of cadmium on unitary EPSP ${ }_{1}$ in a single CA1 cell. $A$ demonstrates the effect of cadmium on $m_{\mathrm{rv}}$, calculated for successive groups of 40 responses, as described in Materials and Methods. $B$, Cadmium effects on $q_{\mathrm{cv}}$ also calculated for groups of 40 responses. $C$ illustrates the relationship between the average EPSP, amplitude $(M)$ and the parameter $m_{\mathrm{cv}}$ before (control), during $\left(C d^{2+}\right)$, and following (wash) superfusion of the hippocampal slice with cadmium. The high degree of correspondence between these two measures, using least-squares linear regression $\left(r^{2}=\right.$ 0.93 ; slope $=7.60 ; p<0.0001$ ), indicates that the effect of cadmium on $m_{\mathrm{cv}}$ is sufficient to account quantitatively for over $90 \%$ of the observed change in $M . D$, Thirty consecutive unitary EPSP responses before (CONTROL) and during superfusion with cadmium chloride.

substrate for adenosine transmembrane transport systems (Williams and Cusack, 1990). CHA caused a qualitatively similar reduction in the average amplitude of unitary EPSPs $(n=5$ cells), reducing these responses to $50 \pm 12 \%$ of control $\left(\mathrm{EPSP}_{1}\right)$ and $54 \pm 11 \%$ of control $\left(\mathrm{EPSP}_{2}\right)$. In a manner that was also similar to adenosine, CHA reduced the parameter $m_{\mathrm{cv}}$ to $58 \pm$ $22 \%$ of control $\left(\mathrm{EPSP}_{1}\right)$ and $52 \pm 16 \%$ of control $\left(\mathrm{EPSP}_{2}\right)$. CHA, similar to adenosine, did not significantly alter $q_{\mathrm{cv}}(98 \pm 17 \%$ of control and $116 \pm 35 \%$ of control, EPSP ${ }_{1}$ and $\mathrm{EPSP}_{2}$, respectively).

Group summaries of all of the above manipulations can be seen in Figure 7, where the relative change in average EPSP size $(M)$ is plotted against the relative change in $m_{\mathrm{cv}}$. One would predict that if $m_{\mathrm{cv}}$ were indeed related to the amount of neurotransmitter released, then $M$ and $m_{\mathrm{cv}}$ should change in parallel and, when plotted, these points should fall along a line possessing a slope of unity. However, if a manipulation decreased average EPSP amplitudes via a postsynaptic mechanism leaving $m_{\mathrm{cv}}$ unaltered, then these points should fall along a horizontal line (i.e., possessing a slope of zero). As Figure 7 illustrates, paired-pulse facilitation, cadmium, adenosine, and CHA treatments all caused a parallel shift in $m_{\mathrm{c} v}$ and $M$. A least-squares fit to these points (not shown) yielded a regression coefficient of $r^{2}=0.98$ and a slope of 1.06 , indicating that the alterations in $m_{\mathrm{cv}}$ were sufficient to account for the changes observed in average EPSP amplitude for these manipulations. This figure also shows that, for DNQX, the significant reduction in average EPSP amplitude occurred independently of significant changes in $m_{\mathrm{cv}}$. The effects of all of manipulations on $m_{\mathrm{cv}}$ and $q_{\mathrm{cv}}$ for EPSP $_{1}$ and EPSP ${ }_{2}$ are summarized in Figure 8, where it can be seen that the only manipulation to reduce $q_{\mathrm{cv}}$ (Fig. $8 B$ ) significantly and to have no significant effect on $m_{\mathrm{cv}}$ was DNQX (Fig. $8 A$ ). Furthermore, this figure shows that the magnitude of facilitation of $m_{\mathrm{cr}}$ for $\mathrm{EPSP}_{2}$ was not significantly altered by any of the pharmacological manipulations.

Comparison of $\mathrm{m}_{c v}$ with $\mathrm{m}_{\mathrm{r}}$. As discussed above, one of the possible interpretations of $m_{\mathrm{cv}}$ is that it estimates the mean quantal content $(m)$ at these synapses. Another way to estimate 
A.

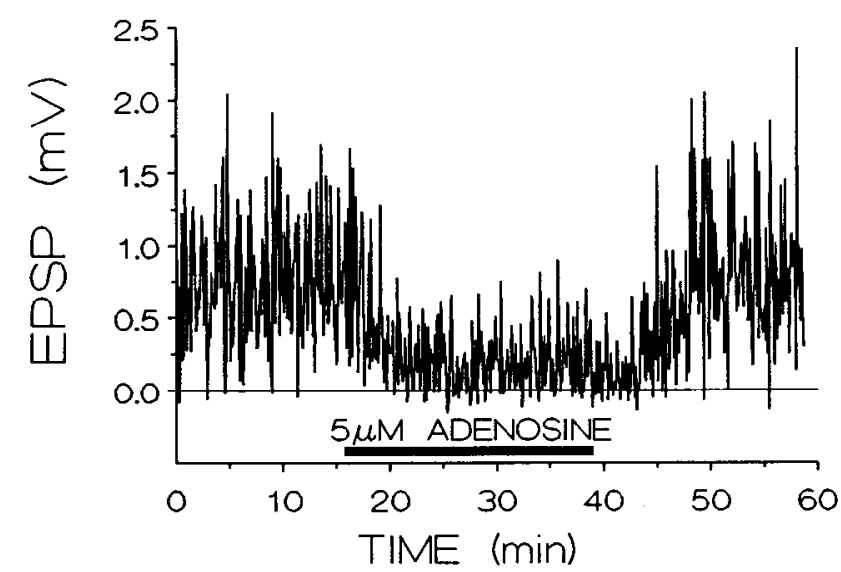

B.

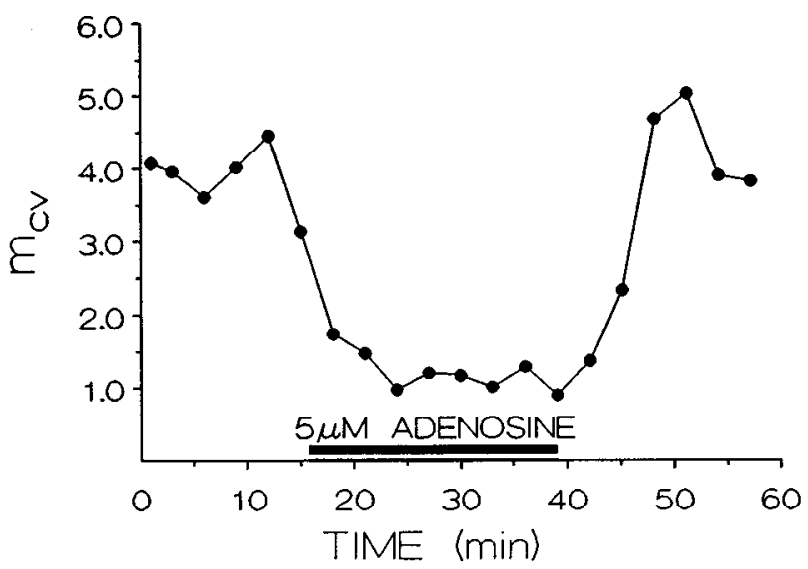

C.

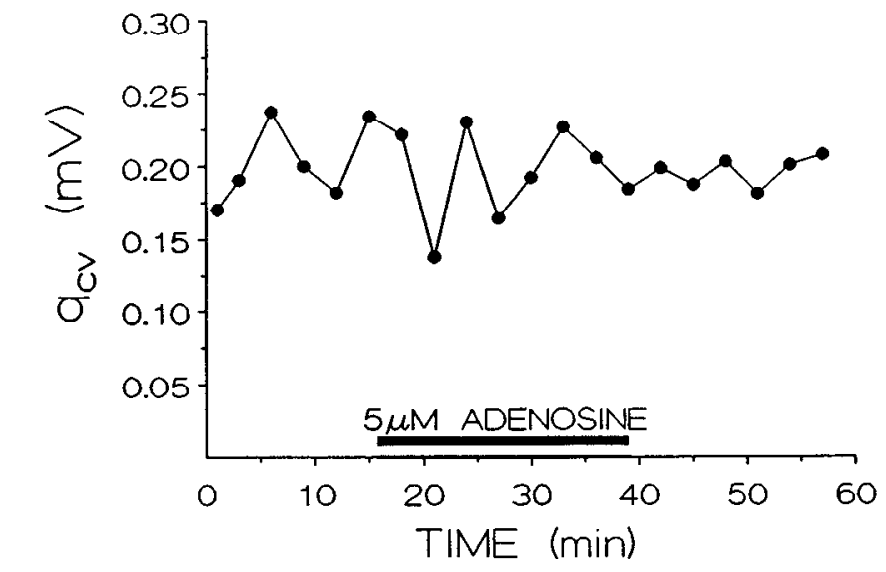

D. EPSP1 EPSP2

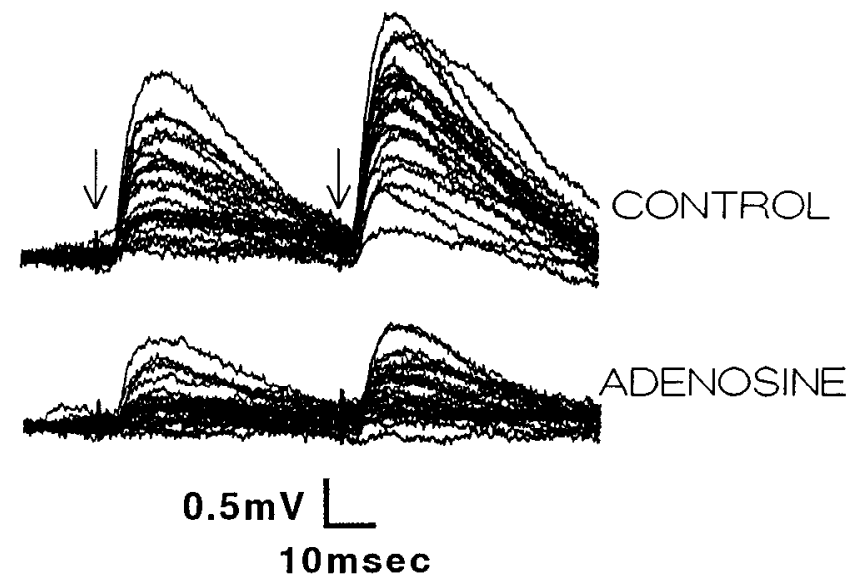

Figure 5. The effects of adenosine on unitary EPSP, and statistical parameters. $A$ illustrates the time course of changes in EPSP ${ }_{1}$ induced by adenosine. $B$, The effect of adenosine on $m_{\mathrm{cv}}$ calculated for groups of 25 responses, as described in Materials and Methods. Note that adenosine reversibly reduced $m_{\mathrm{cv}}$ in a manner that was similar to that of cadmium (Fig. $3 A$ ), but did not affect the parameter $q_{\mathrm{cv}}(C)$. $D$, Individual responses evoked under control conditions and in the presence of adenosine are shown.

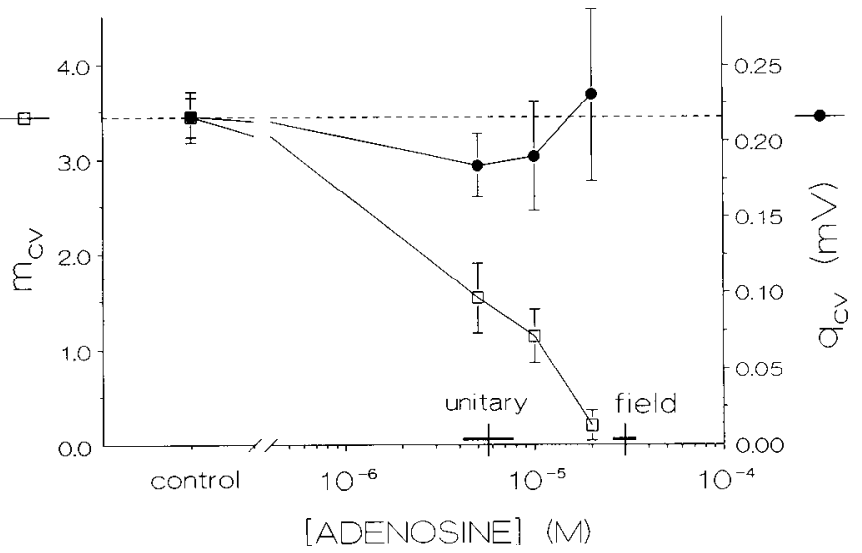

Figure 6. Concentration-dependent reduction of $m_{\mathrm{cv}}$ but not $q_{\mathrm{cv}}$, by adenosine $(F=12.9 ; \mathrm{df}=35 ; p<0.0001$, ANOVA). Each point in the concentration-response curve represents the mean of 5 to 17 cells tested with the indicated concentration of adenosine. A total of 17 cells were used to determine the $\mathrm{EC}_{50}$, indicated by the vertical line labeled unitary on the abscissa; the horizontal bar indicates the $95 \%$ confidence limits for the estimate of the $\mathrm{EC}_{50}$. Note that the $\mathrm{EC}_{50}$ value for the reduction $m$ is to use the method of failures $\left(m_{f}\right)$ (del Castillo and Katz, 1954a,b; Martin, 1966; Hubbard et al., 1969). Figure 9 illustrates the relationship between $m_{\mathrm{cv}}$ and $m_{f}$ for all cells that demonstrated at least two failures during the control and drug application period (calculated from $\mathrm{EPSP}_{1}$ only; $\mathrm{EPSP}_{2}$ showed so few failures that this approach could not be used). In general, the correlation between values obtained using $m_{\mathrm{cv}}$ and $m_{f}$ was high $\left(r^{2}=0.83\right.$; slope $=1.2 ; p<0.0001$; solid line, Fig. 9). The greatest correspondence between $m_{\mathrm{cv}}$ and $m_{f}$ was obtained when these values were less than $\sim 2$, while the largest consistent deviations from a slope of unity (broken line, Fig. 9) were seen when these values were larger than $\sim 2$, or in the presence of DNQX (mean $m n_{\mathrm{cv}}=4.1 \pm 1.3$; mean $\left.m_{f}=1.7 \perp 0.3\right)$. Generally,

of extracellular field EPSPs (vertical line labeled field) was significantly greater than for unitary EPSPs (Dunwiddie and Hoffer, 1980). The $\mathrm{EC}_{50}$ derived from experiments with large EPSPs recorded with conventional intracellular electrodes $(33 \mu \mathrm{M})$ was also larger than the $\mathrm{EC}_{50}$ for unitary EPSPs (Proctor and Dunwiddie, 1987). In this and all subsequent figures, error bars represent 1 SEM. 

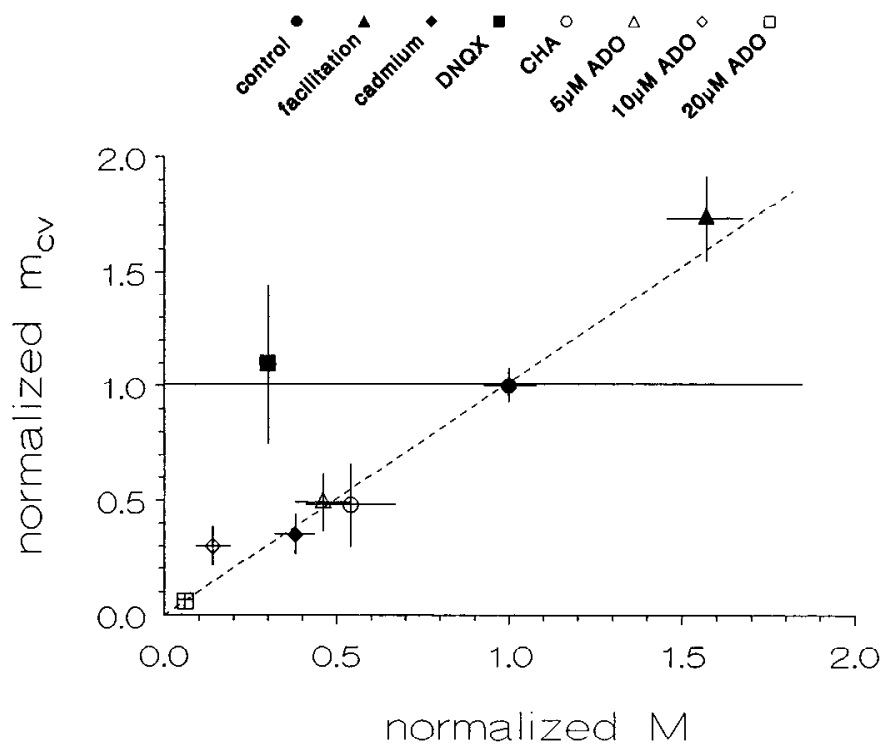

Figure 7. Effects of all manipulations upon the relationship between mcan EPSP amplitude $(M)$ and $m_{\mathrm{cv}}$. All symbols represent averages obtained from 5-17 cells, normalized to the control EPSP ${ }_{1}$ average. Facilitation refers to the effect of a preceding stimulus on a second response $\left(\mathrm{EPSP}_{2}\right)$ during the control condition in all cells. Note that the effect of the first stimulus on the second response causes a nearly equivalent increase in $m_{\mathrm{c} v}$ and $M$, supporting the conclusion that synaptic facilitation is a presynaptic form of plasticity. The broken diagonal line represents one-to-one correspondence between $M$ and $m_{\mathrm{cv}}$, not a regression fit. As can be seen from this figure, all of the manipulations affected $M$ and $m_{\mathrm{cv}}$ approximately equally except for DNQX, which significantly reduced mean EPSP amplitude without altering $m_{\mathrm{cv}}$.

the pharmacological manipulations that reduced $m_{\mathrm{cv}}$ also reduced $m_{f}$ to the same degree.

\section{Discussion}

The results of the present investigation suggest that the technique of statistical analysis of synaptic variability, together with the enhanced signal-to-noise ratio provided by the whole-cell

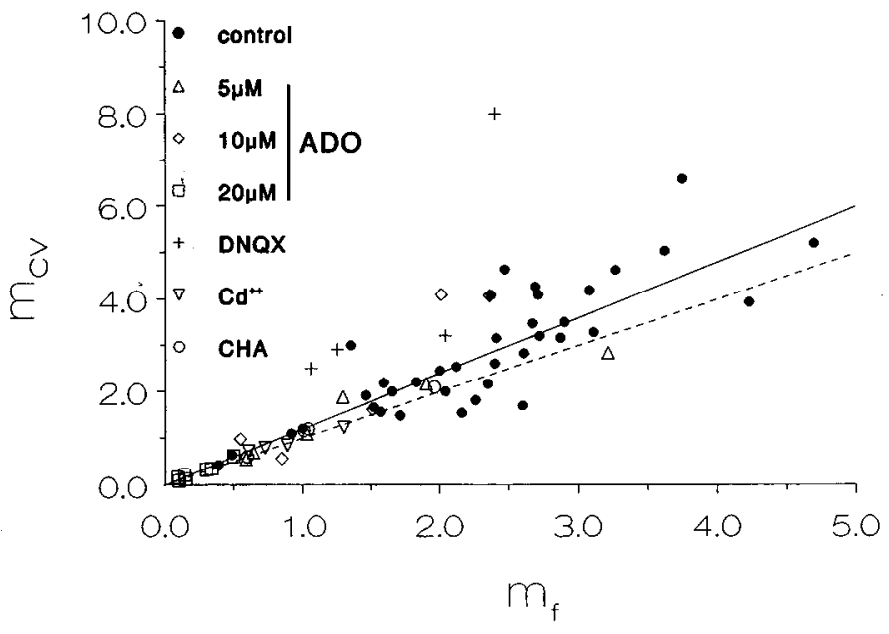

Figure 9. Comparison of estimates of quantal content calculated using $m_{\mathrm{cv}}$ and the method of failures $\left(m_{f}\right)$ during control periods and during the indicated pharmacological manipulations. $A D O$, adenosine; $D N Q X$, $1 \mu \mathrm{M}$ DNQX; $C d^{2+}, 10 \mu \mathrm{M}$ cadmium chloride; $C H A, 5 \mathrm{nM}$ CHA. The correlation between $m_{\mathrm{cv}}$ and $m_{f}$ was high $\left(r^{2}=0.83\right.$; slope $=1.2 ;$ solid line); however, there was a tendency for points to fall above a line with a slope of unity (broken line) when $m$ was large. Note that DNQX caused a reduction in $m_{f 3}$ which probably resulted from a reduction of the parameter $q_{\mathrm{cv}}$ to a level that was difficult to distinguish from background recording noise, and hence resulted in a greater number of observed failures.

recording configuration, can be useful in the determination of the site of action of drugs that modify synaptic transmission. This technique has also been useful in the evaluation of the loci of changes induced by physiological manipulations known to cause long-term alterations in synaptic plasticity (Bekkers and Stevens, 1990; Malinow and Tsien, 1990; Foster and McNaughton, 1991; Renner et al., 1991), although there still remains considerable controversy concerning these results (Korn and Faber, 1991). Since only a small portion of the variability in our recordings of unitary EPSPs could bc ascribcd to the background recording noise, it is reasonable to assume that the ma-

$$
\text { A. }
$$
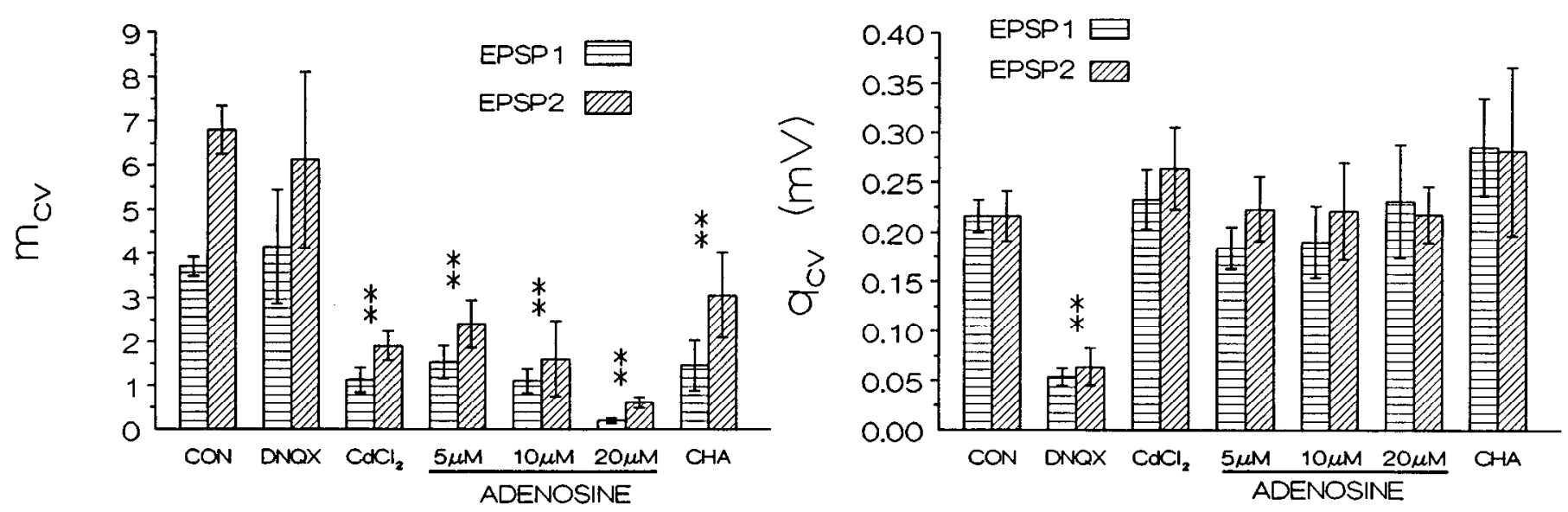

Figure 8. A summary of the effects of all treatments on $m_{\mathrm{cv}}(A)$ and $q_{\mathrm{cv}}(B)$ calculated for both $\mathrm{EPSP}_{1}$ and EPSP. Adenosine, the adenosine A1 receptor selective agonist CHA $(5 \mathrm{nM})$, and cadmium $\left(\mathrm{CdCl}_{2}, 10 \mu \mathrm{M}\right)$ all produced essentially equivalent reductions in $m_{\mathrm{cv}}$, with no change in $q_{\mathrm{cv}}$. DNQX was the only agent to reduce $q_{\mathrm{cv}}$ (from approximately 200 to $50 \mu \mathrm{V}$ ), but had no effect on $m_{\mathrm{cv}}{ }^{* *}, p<0.001$ compared to control (ANOVA). 
jority of this variance was due to biological factors. The question, with regard to the usefulness of the statistical measures employed in the present investigation, then becomes, what is the source of this high degree of response variability'?

First, among the many possible presynaptic factors that may account for the high degree of unitary EPSP variability is that the extracellular electrical stimulation used to elicit EPSPs actually activated a varying number of presynaptic axons. This would result in a situation where $m_{\mathrm{cv}}$ and $m_{f}$ might actually represent the average number of nerve terminals activated by the stimulation, and not the average number of quanta released by a given presynaptic stimulus. This would imply that the reductions in $m_{\mathrm{cr}}$ and $m_{f}$ seen with cadmium, adenosine, and CHA were due to an alteration in axonal excitability and not mean quantal content. We have examined this possibility, specifically, with reference to adenosine, using extracellular recording of presynaptic fiber spikes in the absence of postsynaptic glutamate responses (high concentrations of DNQX and the NMDA antagonist D,L-2-amino-5-phosphonovalerate in the medium were used to block synaptic responses). We have found that while adenosine does significantly reduce these presynaptic fiber potentials, this effect is blocked by removing the CA3 area of the slice (K. Miller and T. V. Dunwiddie, unpublished observations). This suggests that adenosine reduces the presynaptic fiber spike (and axonal excitability) via hyperpolarization of CA3 pyramidal neuron somata and Schaffer collaterals by activating adenosine receptors located only on CA3 pyramidal neuron somata. Since, in the present study, we removed the CA3 region of our slices prior to unitary EPSP recordings, it is unlikely that differences in axonal excitability can account for the reductions in $m_{\mathrm{cr}}$ and $m_{f}$ seen with adenosine or CHA. It is also unlikely that cadmium, at the concentration used in this study $(10 \mu \mathrm{M})$, reduced $m_{\mathrm{cv}}$ and $m_{f}$ by altering axonal excitability, since its best-documented action is to block voltagesensitive $\mathrm{Ca}^{2+}$ channels (Fox et al., 1987; Hille, 1992). Furthermore, it is more plausible that an increase in $m$ accounts for the enhancement of EPSPs with paired pulses of equal magnitude, rather than a greater number of stimulated axons upon the second stimulus.

A second possible source of the EPSP variahility might be a wide range in the amplitudes of individual quanta $(q)$. If this were the case, then any changes in $m_{\mathrm{cr}}$ and $m_{f}$ might be due to alterations in the size and variance of quantal amplitudes. The possibility that quantal amplitude may be variable at Schaffer collateral-commissural synapses has been addressed by a few investigators. Larkman et al. (1991) found that peaks (fitted using the maximum likelihood estimator) seen in amplitude histograms of $\sim 1000$ unitary EPSPs were equally spaced and had similar SD values. Similarly, Edwards et al. (1990), studying inhibitory synaptic inputs to dentate granule cells, have suggested that quantal amplitudes are stationary at these synapses. However, this group has proposed that the uniformity of quantal amplitudes is determined not presynaptically by invariant vesicle size, but postsynaptically by a fixed number of receptors that are saturated by the contents of a single synaptic vesicle (Edwards et al., 1990; Edwards, 1991). Clearly, this latter hypothesis challenges the validity of using quantal release statistics based upon simple binomial models. However, the results of both Larkman et al. (1991) and Edwards et al. (1990) suggest that quantal amplitudes are invariant at these synapses, and that quantal variability cannot account for the high degree of variance of unitary EPSPs at Schaffer collateral-commissural syn- apses. In contrast to these studies demonstrating uniform quantal amplitudes, a study conducted using synaptically connected pyramidal neurons in culture demonstrated that the high degree of EPSP variability could be explained by the variance in quantal size, possibly due to a wide range of presynaptic vesicle sizes (Bckkcrs ct al., 1990). Thus, it is difficult to draw conclusions from these studies as to the uniformity of quantal size in the CNS, and our own data do not provide sufficient information to resolve this issue, particularly without accurate measurement of spontaneous miniature EPSPs observed at the same synapse(s). Furthermore, histograms describing our data do not generally show clearly differentiated peaks corresponding to the release of one, two, three quanta, and so on (see Fig. 2), though our sample sizes were not large compared to those of Larkman et al. (1991), for example. Nevertheless, if the source of variability was variation in quantal amplitude, our results would suggest that adenosine, cadmium, and the initial response of a closely spaced pair of responses (i.e., paired pulses) are all capable of changing the size of individual quanta, and this seems unlikely.

A third possibility is that one of a variety of postsynaptic altcrations could govern the high degree of variability seen in unitary EPSP responses. A few of these are trial to trial alterations in the number of functional postsynaptic receptors, large fluctuations in the probabilities of channel openings, alterations in neurotransmitter uptake and degradation systems, brief local changes in resting membrane potential, or variations in voltageactivated conductances that may shunt EPSPs (Korn and Faber, 1991). However, since responses to locally applied glutamate, albeit larger than those reported here, typically do not show this type of variability (Proctor and Dunwiddie, 1987; Hvalby, 1990), and since ultrastructural and biochemical data have not been presented to support one or more of these alternatives, they must be treated as tenable though unlikely hypotheses.

A final possibility is that the high degree of EPSP variance results from trial to trial variability in the number of quanta released $(m)$. Support for this hypothesis is derived from the close agrecment between the present findings and the predicted results for a number of experimental manipulations that should change $m$ and $q$ in well-established ways. Thus, the predictions that the conditioning pulse of a pair will cause facilitation of the second response that can be explained by an increase in $m$ (Hess et al., 1987; Foster and McNaughton, 1991), and the decrease in $m$ caused by limiting $\mathrm{Ca}^{2+}$ availability to nerve terminals comes from the original description of these phenomena by del Castillo and Katz $(1954 a, b)$ at the neuromuscular junction. Similarly, the prediction that DNQX should reduce $q_{\mathrm{cv}}$ but not $m_{\mathrm{cr}}$ was also supported by our data. In this context, the observation that adenosine reduced $m_{\mathrm{cv}}$ but not $q_{\mathrm{cv}}$ is quite consistent with the effects that have been described for adenosine in numerous studies at the neuromuscular junction (Ginsborg and Hirst, 1972; Ribeiro and Walker, 1975; Silinsky, 1984; Ribeiro and Sebastiao, 1985). Thus, the present results describe changes in our cstimatcd parameters that, in every case, are consistent with those seen in a variety of preparations. Additionally, our estimate of $q_{\mathrm{cv}}$ determined at Schaffer collateralcommissural synapses agrees quantitatively with previous studies that utilized a variety of techniques to estimate this parameter in the CNS (McNaughton et al., 1981; Yamamoto, 1982; Hess et al., 1987; Sayer et al., 1989, 1990; Friedlander et al., 1990; Foster and McNaughton, 1991; Yamamoto et al., 1991).

The evidence provided by these experiments demonstrates 
that the primary action of adenosine in the hippocampus is to act upon presynaptic receptors to limit excitatory neurotransmitter release. This is supported by the observation that adenosine concentration-dependently reduced average unitary EPSP amplitudes and $m_{\mathrm{cv}}$ values in parallel, without significantly affecting $q_{\mathrm{cv}}$ or resting membrane potential. Furthermore, the similarity between CHA and adenosine on these parameters suggests that the reduction of synaptic transmission by adenosine occurred through the activation of presynaptic Al receptors. These results are consistent with previous reports using lessdirect measures of neurotransmitter release in the CNS (Michaelis et al., 1979; Dunwiddie and Hoffer, 1980; Jonzon and Fredholm, 1984; Feuerstein et al., 1985; Jackisch et al., 1985; Burke and Nadler, 1988; Haas and Greene, 1988; Dunwiddie and Fredholm, 1989; Lupica et al., 1990) and with studies of the effects of adenosine upon quantal neurotransmitter release at the neuromuscular junction (Ginsborg and Hirst, 1972; Ribeiro and Walker, 1975; Silinsky, 1984). Thus, the reduction in quantal content $(m)$ at nerve-muscle synapses without alteration of the average size of a quantum of neurotransmitter $(q)$ is consistent with its reduction in $m_{\mathrm{cv}}$ and the absence of its effects on $q_{\mathrm{cv}}$ in the present study. The lack of effects of adenosine on $q_{\mathrm{cv}}$ and the prominent reduction of $m_{\mathrm{cv}}$ were mimicked by the $\mathrm{Ca}^{2+}$ channel blocker cadmium, providing further support for the presynaptic locus of adenosine's actions. Furthermore, the effects of elevating $\mathrm{Ca}^{2+}$ or lowering $\mathrm{Mg}^{2+}$ concentrations on $m_{\mathrm{cv}}$ have been described previously, and these manipulations are consistent with an enhancement of presynaptic function (Malinow and Tsien, 1990). The results of the present study are also in agreement with those of Scholz and Miller (1991), who demonstrated that the inhibitory effects of adenosine on monosynaptic EPSPs in cell culture were primarily presynaptic, and mediated by an A1 receptor.

An unexpected finding of this investigation was that the $50 \%$ effective concentration of adenosine for the inhibition of $m_{\mathrm{cv}}$ $(\sim 6 \mu \mathrm{M})$ was approximately fivefold lower than $\mathrm{EC}_{50}$ values for adenosine's reduction of larger EPSPs, recorded with conventional high-resistance microelectrodes, and extracellular field EPSPs, both elicited by activation of Schaffer collateral-commissural inputs to CAl pyramidal neurons (Dunwiddie and Hoffer, 1980; Proctor and Dunwiddie, 1987). The reduced potency of adenosine with larger EPSPs may be explained by the phenomenon of nonlinear summation of quanta at these synapses. Thus, the reduction of EPSP amplitude by adenosine would be diminished with increasingly larger EPSPs, since the contribution of each quantum to this response becomes less with further depolarization of the postsynaptic membrane (Martin, 1966). This possibility was specifically investigated using extracellular measurements of EPSPs in hippocampus, where it was found that adenosine inhibited small field EPSPs to a greater degree than larger responses (Dunwiddie, 1984). Other possibilities are that the low-intensity unitary EPSP stimulation selectively activates a subpopulation of nerve terminals that are more sensitive to adenosine, or that a novel adenosine receptor is present on low-threshold fibers. Regardless of which possibility is correct, the $\mathrm{EC}_{50}$ of adenosine for the inhibition of $m_{\mathrm{cv}}$ in the present study is quite close to the estimated concentration of endogenous adenosine distributed in the extracellular space in the hippocampus (i.e., 1-2 $\mu \mathrm{M}$ ) (Zetterstrom et al., 1982; Fredholm et al., 1984) and supports the suggestion that adenosine exerts a tonic inhibition of normal synaptic transmission in CA1 (Dunwiddie et al., 1981; Haas and Greene, 1988).

There are at least two possible explanations for the absence of significant postsynaptic actions of adenosine on resting membrane potential (and, indirectly, upon $q_{\mathrm{cv}}$ ) in the present study. First, the concentration at which adenosine was $50 \%$ effective at reducing $m_{\mathrm{cv}}(\sim 6 \mu \mathrm{M})$ is approximately fivefold lower than its $\mathrm{EC}_{50}$ at postsynaptic adenosine receptors (Dunwiddie and Fredholm, 1989). Second, during whole-cell recording in the absence of GTP in the patch pipette, the activation of the G-protein-linked potassium conductance that mediates the postsynaptic hyperpolarizing response to adenosine is nearly absent within 15 min of rupturing the membrane patch (Trussell and Jackson, 1987). Since our recording protocol required at least 15 min of unitary EPSP recording prior to the administration of adenosine, and since we did not include GTP in our pipette filling solution, it is likely that all G-protein-mediated responses were virtually eliminated in the patched cells. Thus, the absence of postsynaptic effects of adenosine can most likely be explained by these factors.

The only pharmacological manipulation in the present study that had no effect upon the parameter $m_{\mathrm{cv}}$ was the addition of the non-NMDA glutamate receptor antagonist DNQX, even though DNQX reduced average EPSP amplitudes substantially. This is in agreement with the findings of Malinow and Tsien (1990), where a similar glutamate receptor antagonist (i.e., 6-cyano-7-nitroquinoxaline-2,3-dione [CNQX]) was found to reduce average EPSP amplitudes without altering $m_{\mathrm{cv}}$. They did not, however, calculate $q_{\mathrm{cv}}$, which was clearly reduced by DNQX in the present study. Reductions in $q_{\mathrm{cv}}$ by DNQX could reflect a presynaptic action, if it reduced vesicular neurotransmitter content $(v)$, or a postsynaptic action to reduce glutamate sensitivity (Andreasen et al., 1988, 1989; Herreras et al., 1989). This latter mechanism is consistent with the known ability of DNQX to bind to glutamate receptors. DNQX may thus provide a useful tool for comparison with other pharmacological manipulations suspected of acting postsynaptically to reduce synaptic efficacy.

The values of $m_{f}$ in the presence of DNQX were probably underestimated because of the prominent reduction of $q_{\mathrm{cv}}$ by this antagonist. Thus, as quantal content decreases it becomes increasingly difficult to distinguish the diminished unitary responses from the background recording noise, and the smallest responses will be incorrectly labeled as "failures." This has been previously noted as a caveat of the method of failures when the baseline amplitude of $q$ is small (Korn and Faber, 1991), as is apparently the case at central synapses (Bekkers et al., 1990; Foster and McNaughton, 1991; Larkman et al., 1991; Yamamoto et al., 1991). However, the prominent and consistent reduction in $q_{\mathrm{c}}$ by DNQX in the present study (approximately fourfold reduction; Figs. 3,8) suggests that this parameter is sufficiently larger than the background recording noise in our preparation, and that the qualitative estimates of changes in this parameter are accurate, though the maximal effect of DNQX at the concentration used $(1 \mu \mathrm{M})$ may have been underestimated.

The effects of DNQX on $m_{f}$ notwithstanding, the high degree of correspondence between $m_{\mathrm{cv}}$ and $m_{f}$ demonstrates that these measures of synaptic efficacy arrive at similar estimates under most conditions. The finding that $m_{\mathrm{cv}}$ usually overestimated mean quantal content as estimated by $m_{f}$ was not surprising since it has been noted that $m_{\mathrm{cv}}$ overestimates mean quantal content when the probability of release $(p)$ is large and the sample size is relatively small (del Castillo and Katz, 1954b; Martin, 1966; McLachlan, 1978; Foster and McNaughton, 1991; Yamamoto et al., 1991).

In summary, the results of this investigation show that aden- 
osine, the selective adenosine $\mathrm{A} 1$ agonist $\mathrm{CHA}$, and the calcium channel blocker, cadmium, all reduce unitary EPSP amplitude via what appears to be a presynaptic mechanism. The glutamate receptor antagonist DNQX was also found to reducc unitary EPSP amplitudes, most likely by reducing transmitter sensitivity postsynaptically. The origin of the high degree of variability seen with unitary EPSP recording is not entirely clear. Although the most likely possibility is that it arises from variability in the number of quanta released at excitatory synapses, but other possibilities cannot be eliminated.

\section{References}

Andreasen M, Lambert JD, Jensen MS (1988) Direct demonstration of an $N$-methyl-D-aspartate receptor mediated component of excitatory synaptic transmission in area CA1 of the rat hippocampus. Neurosci Lett 93:61-66.

Andreasen M, Lambert JD, Jensen MS (1989) Effects of new non- $N$ methyl-D-aspartate antagonists on synaptic transmission in the in vitro rat hippocampus. J Physiol (Lond) 414:317-336.

Bekkers JM, Stevens CF (1990) Presynaptic mechanism for long-term potentiation in the hippocampus. Nature 346:724-729.

Bekkers JM, Richerson GB, Stevens CF (1990) Origin of variability in quantal size in cultured hippocampal neurons and hippocampal slices. Proc Natl Acad Sci USA 87:5359-5362.

Burke SP, Nadler JV (1988) Regulation of glutamate and aspartate release from slices of the hippocampal CAl arca: effects of adenosinc and baclofen. J Neurochem 51:1541-1551.

Creager R, Dunwiddie TV, Lynch GS (1980) Paired-pulse and frequency facilitation in the CAl region of the in vitro rat hippocampus. J Physiol (Lond) 299:409-424.

del Castillo J, Katz B (1954a) Statistical factors involved in neuromuscular facilitation and depression. J Physiol (Lond) 124:574-585.

del Castillo J, Katz B (1954b) Quantal components of the end-plate potential. J Physiol (Lond) 130:374-395.

Dunwiddie TV (1984) Interactions between the effects of adenosine and calcium on synaptic responses in rat hippocampus in vitro. $\mathbf{J}$ Physiol (Lond) 350:545-559.

Dunwiddie TV (1985) The physiological role of adenosine in the central nervous system. Int Rev Neurobiol 27:63-139.

Dunwiddie TV, Fredholm BB (1989) Adenosine A1 receptors inhibit adenylate cyclase activity and neurotransmitter release and hyperpolarize pyramidal neurons in rat hippocampus. J Pharmacol Exp Ther 249:31-37.

Dunwiddie TV, Hoffer BJ (1980) Adenine nucleotides and synaptic transmission in the in vitro rat hippocampus. $\mathrm{Br} \mathrm{J}$ Pharmacol 69:5968.

Dunwiddie TV, Hoffer BJ, Fredholm BB (1981) Alkylxanthines elevate hippocampal excitability: evidence for a role of endogenous adenosine. Naunyn Schmiedebergs Arch Pharmacol 316:326-330.

Dunwiddie TV, Lupica CR, Proctor WR (1991) Unitary EPSPs measured by whole-cell recording are reduced by adenosine in rat hippocampal CAl pyramidal neurons in vitro. Soc Neurosci Abstr 17: 1548.

Edwards FA (1991) LTP is a long-term problem. Nature 350:271272.

Edwards FA, Konnerth A, Sakmann B (1990) Quantal analysis of inhibitory synaptic transmission in the dentate gyrus of rat hippocampal slices: a patch clamp study. J Physiol (Lond) 430:213-249.

Feuerstein TJ, Hertting F, Jackisch R (1985) Modulation of hippocampal serotonin $(5-\mathrm{HT})$ release by endogenous adenosine. Eur J Pharmacol 107:233-242.

Foster TC, McNaughton BL (1991) I ong-term enhancement of CA1 synaptic transmission is due to increased quantal size, not quantal content. Hippocampus 1:79-91.

Fox AP, Nowycky MC, Tsien RW (1987) Kinetic and pharmacological properties distinguishing three types of calcium currents in chick sensory neurons. J Physiol (Lond) 394:149-172.

Fredholm BB, Dunwiddie TV, Bergman B, Lindstrom K (1984) Levels of adenosine and adenine nucleotides in slices of rat hippocampus. Brain Res 295:127-136.

Friedlander MJ, Sayer RJ, Redman SJ (1990) Evaluation of long-term potentiation of small compound and unitary EPSPs at the hippocampal CA3-CA1 synapse. J Neurosci 10:814-825.
Ginsborg BL, Hirst GDS (1972) The effect of adenosine on the release of the transmitter from the phrenic nerve of the rat. J Physiol (Lond) 224:629-645.

Greene RW, Haas HL (1985) Adenosine actions on CA1 pyramidal neurones in rat hippocampal slices. J Physiol (Lond) 366:119-127.

Haas HL, Greene RW (1988) Endogenous adenosine inhibits hippocampal CA1 neurones: further evidence from extra- and intracellular recording. Naunyn Schmiedebergs Arch Pharmacol 337:561-565.

Herreras.O, Menendez N, Herranz AS, Solis JM, del Rio MR (1989) Synaptic transmission at the Schaffer-CA1 synapse is blocked by 6,7 dinitroquinoxaline-2,3-dione. An in vivo brain dialysis study in the rat. Neurosci Lett 99:119-124.

Hess G, Kuhnt U, Voronin LL (1987) Quantal analysis of pairedpulse facilitation in guinea pig hippocampal slices. Neurosci Lett 77: 187-192.

Hillc B (1992) Ionic channels of excitable membranes. Sunderland, MA: Sinauer.

Hubbard JI, Llinas R, Quastel DMJ (1969) Electrophysiological analysis of synaptic transmission. Baltimore: Williams and Wilkins.

Hvalby O (1990) Dendritic excitation by glutamate in CA1 hippocampal cells. In: Progress in brain research, Vol 89, Understanding the brain through the hippocampus (Storm-Mathisen J, Zimmer J, Ottersen OP, eds), pp 131-139. London: Elsevier.

Jackisch R, Fehr R, Hertting G (1985) Adenosine: an endogenous modulator of hippocampal noradrenaline release. Neuropharmacology 24:499-507.

Jonzon B, Fredholm BB (1984) Adenosine receptor mediated inhibition of noradrenaline release from slices of rat hippocampus. Life Sci 35:1971-1979.

Korn H, Faber DS (1991) Quantal analysis and synaptic efficacy in the CNS. Trends Neurosci 14:439-445.

Larkman A, Stratford K, Jack J (1991) Quantal analysis of excitatory synaptic action and depression in hippocampal slices. Nature 350: 344-347.

Lupica CR, Cass WA, Zahniser NR, Dunwiddie TV (1990) Effects of the selective adenosine A2 receptor agonist CGS 21680 on in vitro electrophysiology, cyclic AMP formation and dopamine release in rat hippocampus and striatum. J Pharmacol Exp Ther 252:1134-1190.

Malinow R, Tsien RW (1990) Presynaptic enhancement shown by whole-cell recordings of long-term potentiation in hippocampal slices. Nature 346:177-180.

Martin AR (1966) Quantal nature of synaptic transmission. Physiol Rev 46:51-66.

McLachlan EM (1978) The statistics of transmittcr relcasc at chemical synapses. In: International review of physiology. Neurophysiology III, Vol 17 (Porter R, ed), pp 49-117. Baltimore: University Park.

McNaughton BL, Barnes CA, Andersen P (1981) Synaptic efficacy and EPSP summation in granule cells of rat fascia dentata studied in vitro. J Neurophysiol 46:952-966.

Michaelis ML, Michaelis EK, Myers SL (1979) Adenosine modulation of synaptosomal dopamine release. Life Sci 24:2083-2092.

Okada Y, Kuroda Y (1980) Inhibitory action of adenosine and adenosine analogs on neurotransmission in the olfactory cortex slice of guinea pig: structure-activity relationships. Eur J Pharmacol 61:137146.

Phillis JW, Wu PH (1981) The role of adenosine and its nucleotides in central synaptic transmission. Prog Neurobiol 16:187-239.

Proctor WR, Dunwiddie TV (1987) Pre- and postsynaptic actions of adenosine in the in vitro rat hippocampus. Brain Res 426:187-190.

Renner P, Manabe T, Kullman DM, Zalutsky RA, Nicoll RA (1991) Analysis of the variability of evoked synaptic currents during longterm potentiation in hippocampal slices. Soc Neurosci Abstr 17:1328.

Ribeiro JA, Sebastiao AM (1985) On the type of receptor involved in the inhibitory action of adenosine at the neuromuscular junction. Br J Pharmacol 84:911-918.

Ribeiro JA, Walker J (1975) The effects of adenosine triphosphate and adenosine diphosphate on transmission at the rat and frog neuromuscular junctions. Br J Pharmacol 54:213-218.

Sayer RJ, Redman SI, Andersen P (1989) Amplitude fluctuations in small EPSPs recorded from CA1 pyramidal cells in the guinea pig hippocampal slice. J Neurosci 9:840-850.

Sayer RJ, Friedlander MJ, Redman SJ (1990) The time course and amplitude of EPSPs evoked at synapses between pairs of CA3/CA1 neurons in the hippocampal slice. J Neurosci 10:826-836.

Scholz KP, Miller RJ (1991) Analysis of adenosine actions on $\mathrm{Ca}^{2+}$ currents and synaptic transmission in cultured rat hippocampal pyramidal neurones. J Physiol (Lond) 435:373-393. 
Schubert P, Mitzdorf U (1979) Analysis and quantitative evaluation of the depressant effect of adenosine on evoked potentials in hippocampal slices. Brain Res 172:186-190.

Silinsky EM (1984) On the mechanism by which adenosine receptor activation inhibits the release of acetylcholine from motor nerve endings. J Physiol (Lond) 346:243-256.

Trussell LO, Jackson MF (1985) Adenosine-activated potassium conductance in cultured striatal neurons. Proc Natl Acad Sci USA 82: $4857-4861$.

Trussell LO, Jackson MB (1987) Dependence of an adenosine-activated potassium current on a GTP-binding protein in mammalian central neurons. J Neurosci 7:3306-3316.

Williams M, Cusack NJ (1990) Neuromodulatory roles of purine nu- cleosides and nucleotides: their receptors and ligands. Neurotransmissions 6:1-6.

Yamamoto C (1982) Quantal analysis of excitatory postsynaptic potentials induced in hippocampal neurons by activation of granule cells. Exp Brain Res 46:170-176.

Yamamoto C, Higashima M, Sawada S, Kamiya H (1991) Quantal components of the synaptic potential induced in hippocampal neurons by activation of granule cells, and the effects of 2-amino-4phosphonobutyric acid. Hippocampus 1:93-106.

Zetterstrom T, Vernet L, Ungerstedt U, Tossman U, Jonzon B (1982) Purine levels in the intact rat brain. Studies with an implanted perfused hollow fibre. Neurosci Lett 29:111-115. 